\title{
Comprehensive breast MRI: an update
}

\author{
Sarah J Vinnicombe ${ }^{1 *}$, Guiseppe Petralia ${ }^{2}$ \\ From International Cancer Imaging Society (ICIS) 14th Annual Teaching Course \\ Heidelberg, Germany. 9-11 October 2014
}

With increasing use of clinical breast MRI and a plethora of novel techniques and sequences for lesion characterisation, a standardised approach to lesion description and reporting is increasingly important. This facilitates meaningful research and audit, particularly in the context of multicentre studies.

To this end the American College of Radiology has recently published the $5^{\text {th }}$ edition of the BI-RADS lexicon, with revision of the MRI section including addition of new descriptors, modification of others and deletion of some that were rarely helpful in practice, such as 'stippled' enhancement [1]. Categories for fibroglandular volume are now a to d, in line with the descriptors for mammography, thus avoiding confusion with assessment category. The degree of background parenchymal enhancement is now purely descriptive, from none/minimal to marked. A new descriptor is clustered rim enhancement (usually indicating DCIS). Non mass-like enhancement becomes non mass enhancement, whereas 'ductal' enhancement becomes linear. Overall the effect is of simplification and consistency with the mammography and ultrasound lexicons.

The lexicon highlights the importance of a structured report, including the indication, scan technique, salient findings and critically, an overall assessment with a clear recommendation for further management. This approach has been validated in a number of studies correlating the assessment category with histopathological findings and/ or long-term follow-up $[2,3]$.

Use of a standardised lexicon, modified in the light of available evidence, has obviated some of the interpretative challenges of breast MRI. Use of supplemental diffusion weighted imaging may also be helpful [4]. Nonetheless, technical and clinical challenges remain. Artefacts are problematic, especially at 3T [5], and medical physics support is essential for good quality diagnostic scans, especially at higher field strength.

Most importantly, it should be remembered that to date, despite the recognised superiority of breast MRI over any other modality for breast cancer detection and local staging, there is no hard evidence for improved patient outcomes. Two randomised controlled trials and seven comparative cohort studies have not shown any benefit for preoperative MRI in terms of re-excision rates; rather, there is a trend to higher mastectomy rates [6]. No convincing beneficial effects have been demonstrated in terms of in-breast tumour recurrence rates, disease-free survival or overall survival. Regarding assessment of response to neoadjuvant chemotherapy, MRI correlates better than mammography or ultrasound with final pathology, but false positive and negative studies are frequent, with underestimation of the amount of residual disease in up to $30 \%$ and overestimation in around $20 \%$ of cases $[7,8]$. Though evidence is accruing that MRI may be helpful in early response assessment, this is by no means standardised and is heavily dependent on many factors, not least tumour immunophenotype. Finally, though screening breast MRI for women at high risk has approximately double the sensitivity of mammography with encouraging stage shift and high rates of node negativity, there is as yet no evidence of a reduction in breast cancer mortality $[9,10]$.

This workshop will provide an update on the BI-RADS lexicon and indications for breast MRI, with expert tuition in hands-on analysis of case studies.

\section{Authors' details \\ 'Division of Imaging and Technology, Medical Research Institute, Ninewells Hospital Medical School, University of Dundee, Dundee, DD1 9SY, UK. ${ }^{2}$ Department of Radiology, European Institute of Oncology, Via Ripamonti 435, 20141 Milan, Italy.}




\section{References}

1. Morris EA, Comstock CE, Lee $\mathrm{CH}$, et al: $\mathrm{ACR}$ BI-RADS ${ }^{\circledR}$ Magnetic Resonance Imaging. In: ACR BI-RADS ${ }^{\circledR}$ Atlas, Breast Imaging Reporting and Data System. Reston, VA, American College of Radiology 2013.

2. Weinstein SP, Hanna LG, Gatsonis C, Schnall MD, Rosen MA, Lehman CD: Frequency of malignancy seen in probably benign lesion at contrastenhanced breast MR imaging: findings from ACRIN 6667. Radiology 2010, 255:731-7.

3. Mahoney MC, Gatsonis C, Hanna L, DeMartini WB, Lehman CD: Positive predictive value of BI-RADS MR imaging. Radiology 2012, 264:51-8

4. Pinker K, Bickel H, Helbich TH, Gruber S, Dubsky P, Pluschnig U, Rudas M, Bago-Horvath Z, Weber M, Trattnig S, Bogner W: Combined contrastenhanced magnetic resonance and diffusion-weighted imaging reading adapted to the "Breast Imaging Reporting and Data System" for multiparametric 3-T imaging of breast lesions. Eur Radiol 2013, 23:1791-802

5. Rahbar H, Partridge SC, DeMartini WB, Thursten B, Lehman CD: Clinical and technical considerations for high quality breast MRI at 3 Tesla. J Magn Reson Imaging 2013, 37:778-90.

6. Houssami N, Turner R, Morrow M: Preoperative magnetic resonance imaging in breast cancer: meta-analysis of surgical outcomes. Ann Surg 2013, 257:249-55.

7. Yuan Y1, Chen XS, Liu SY, Shen KW: Accuracy of MRI in prediction of pathologic complete remission in breast cancer after preoperative therapy: a meta-analysis. Am J Roentgenol 2010, 195:260-8.

8. Lobbes M, Prevos R, Smidt M, Tjan-Heijnen V, van Goethem M, Schipper R Beets-Tan RG, Wildberger JE: The role of magnetic resonance imaging in assessing residual disease and pathologic complete response in breast cancer patients receiving neoadjuvant chemotherapy: a systematic review. Insights Imaging 2013, 4:163-75.

9. Warner E, Hill K, Causer P, Plewes D, Jong R, Yaffe M, Foulkes WD, Ghadirian P, Lynch H, Couch F, Wong J, Wright F, Sun P, Narod SA: Prospective study of breast cancer incidence in women with a BRCA1 or BRCA2 mutation under surveillance with and without magnetic resonance imaging. J Clin Oncol 2011, 29:1664-9.

10. Møller P, Stormorken A, Jonsrud C, Holmen MM, Hagen Al, Clark N, Vabø A, Sun P, Narod SA, Mæhle L: Survival of patients with BRCA1-associated breast cancer diagnosed in an MRI-based surveillance program. Breast Cancer Res Treat 2013, 139:155-61.

doi:10.1186/1470-7330-14-S1-039

Cite this article as: Vinnicombe and Petralia: Comprehensive breast MRI: an update. Cancer Imaging 2014 14(Suppl 1):O39.

\section{Submit your next manuscript to BioMed Central and take full advantage of:}

- Convenient online submission

- Thorough peer review

- No space constraints or color figure charges

- Immediate publication on acceptance

- Inclusion in PubMed, CAS, Scopus and Google Scholar

- Research which is freely available for redistribution

Submit your manuscript at www.biomedcentral.com/submit
Ciomed Central 